\title{
Karyological Studies on Five Egyptian Species of Dictyoptera (Pterygota: Insecta)
}

\author{
Ahmed E. Yaseen, ${ }^{1}$ F. M. Mostafa ${ }^{1}$ and I. S. Kawashti ${ }^{2}$ \\ ${ }^{1}$ Cytogenetic Laboratory, Zoology Department, Faculty of Science (Qena), \\ South Valley University, Egypt \\ ${ }^{2}$ Zoology Department, Faculty of Science, Al-Azhar University, Egypt
}

Accepted June 5, 1996

In recent years cytogenetic studies have been significant contribution to the development of animal taxonomy. Cytotaxonomists are concerned with chromosome different (i.e. number and structure) which exist between different races, species and higher taxonomic levels. Such differences are useful in distinguishing cryptic species that can not be separated morphologically (White 1973).

Cytogenetic studies of chromosome number and morphology of insects are of special interest to taxonomists and evolutionists, not only because class Insecta contain a huge number of species surpasses the number of species contained in all other classes, but also because species of this class show extreme diversity in their biology, morphology and taxonomy (Cohen and Roth 1970).

The chromosome number of only a few of the more than 4000 species of cockroaches are known. Piza (1958) and Cochran and Ross (1967a, b) have reported on the chromosome number of 20 species of Blattaria. Cohen and Roth (1970) reported the chromosome number of 106 species of cockroaches belonging to 62 genera. The diploid chromosome number in order Dictyoptera varied greatly which ranged from 16 to 80 in females and 15 to 79 in males.

Although there has been considerable developments in the field of cytotaxonomic studies in the last twenty years, very little information are available on the chromosomal characters of insects in Egypt. Therefore the aim of the present work is to describe the karyotypes of these five species. Periplaneta americana, Blattella germanica, Supella supellectilium, Mantis religiosa and Sphadromatis bioculata.

\section{Material and methods}

Specimens of the five species Periplaneta americana, Blattella germanica, Supella supellectilium, Mantis religiosa and Sphadromantis bioculata were collected from different localities at Qena City. They were kept alive in cages and fed regularly to promote somatic growth. Suitable adult males and females were selected and injected in abdomen with doses of 0.02 to $0.05 \mathrm{ml}$ of $0.05 \%$ colchicine.

Chromosomal analysis was carried out by the air drying method of Salemaa (1979) with some modification made by Galian et al. (1992) as follows: Specimens were dissected in saline solution, testes and ovaries were removed and instantly immersed in 1\% sodium citrate solution and incubated for $10 \mathrm{~min}$ at room temperature. The tissues were then fixed in ethanol acetic acid $(3: 1)$. A drop of the cell suspension was pipetted out and placed on heated clean glass slides. The dried slides were stained for $20 \mathrm{~min}$ by $2 \%$ Giemsa solution $(\mathrm{pH} 6.8)$ at room temperature.

Suitable metaphase plates were photographed. The fundamental number (FN) was calculated on the basis that metacentrics, submetacentrics and subtelocentrics having a value of 
four and telocentrics has a value of two. Measurements and calculations were made. Centromeric position is described according to criteria established by Levan et al. (1964).

\section{Results and discussion}

Family: Blattidae

Periplaneta americana: The cell spread and karyotype of a model sample of this species (Figs. 1A, B, 2A, B) demonstrated that the diploid chromosome number is $32+\mathrm{XX}$ in females and $32+\mathrm{XO}$ in males and $\mathrm{FN}=62$. The karyotype showed four groups of chromosomes: Group A is composed of seven metacentric pairs (arm ratio: 1.19-1.39), the chromosome pair of number 2 carry secondary constrictions near the centromeres in both the female and male karyotypes, group B is composed of six metacentric (arm ratio: 2.04-2.56), group C have two paris of subtelocentric (arm ratio: 3.33-4.06) and one pair telocentric. The sex chromosome is metacentric with arm ratio 1.15. The metrical analysis are shown in Table 1.
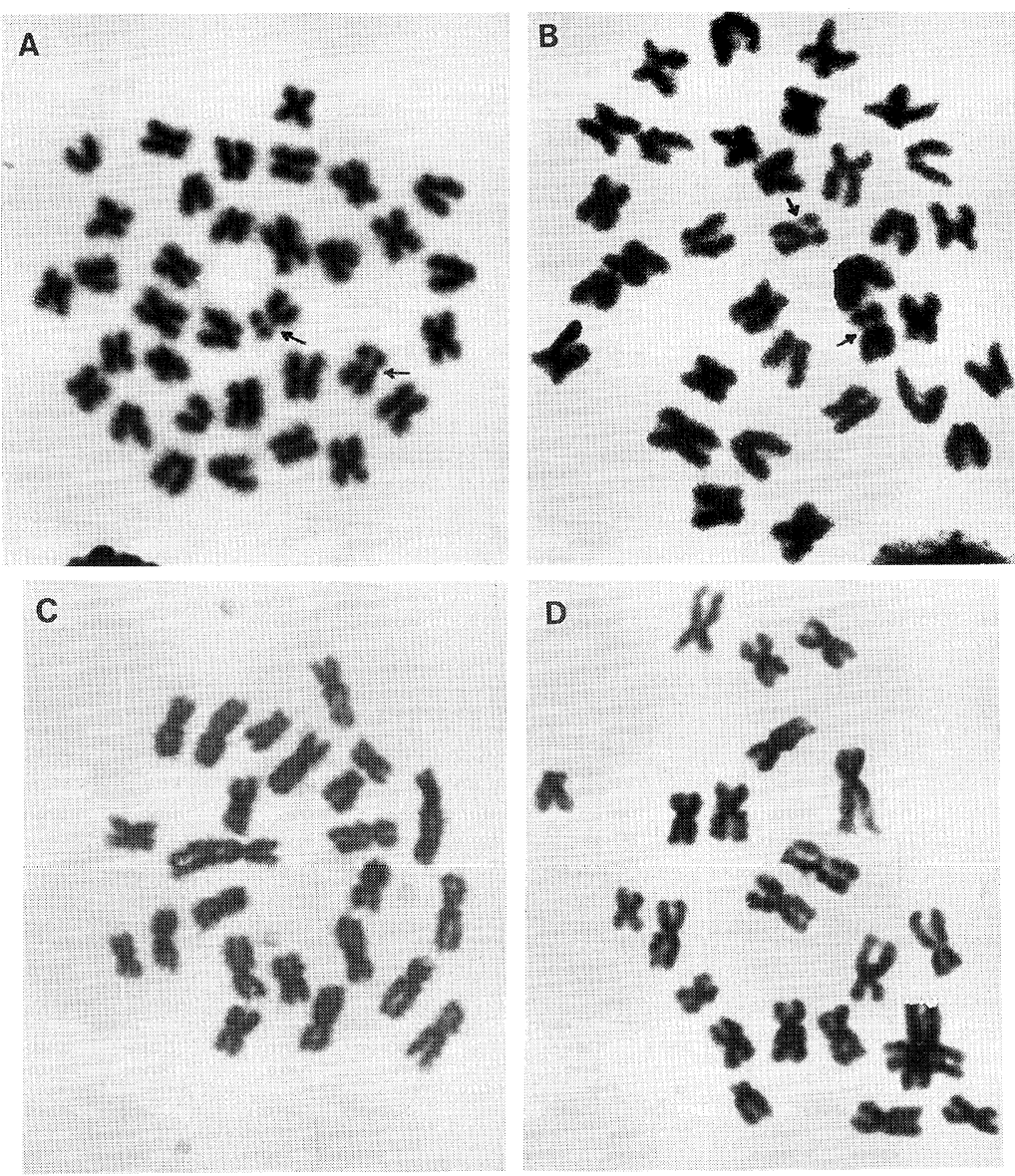

Fig. 1. Mitotic metaphase spreads: (A, B) female and male Periplaneta americana $2 \mathrm{n}=34,33$; (C, D) female and male Blatella germanica $2 \mathrm{n}=24,23 ;(\mathrm{E}, \mathrm{F})$ female and male Supella supellectilium $2 \mathrm{n}=20,19 ;(\mathrm{G}, \mathrm{H})$ female and male Mantis religiosa $2 \mathrm{n}=28,27$; (I, J) female and male Sphadromantis bioculata $2 \mathrm{n}=24,23$ respectively. The arrows indicate the secondary constrictions. 
Family: Blattillidae

1. Blattella germanica: A typical example of cell spread and karyotype of a model sample of this species (Figs. 1C, D, 2C, D) were found to have a diploid chromosome number of $22+\mathrm{XX}$ in females and $22+\mathrm{XO}$ in males. The karyotype showed two groups of chromosomes: Group A is composed of nine pairs of metacentric chromosomes in a graded series arranged descending from large to small size (arm ratio: 1.09-1.40) and group B which have two pairs of submetacentric (arm ratio: 1.83-1.87). The sex chromosome is submetacentric (arm ratio 1.95). The chromosome measurements are given in Table 2.

2. Supella supellectilium: The cell spread and karyotype of this species (Figs. 1E, F, 2E, F) demonstrated that the diploid chromosome number is $18+\mathrm{XX}$ in females and $18+\mathrm{XO}$ in males and $\mathbf{F N}=36$. The karyotype showed three different groups of chromosome pairs: Group A is composed of three pairs of large metacentric chromosome (arm ratio: 1.20-1.27), group B is composed of five pairs of large submetacentric chromosomes (arm ratio: 3.55-3.83), group $\mathrm{C}$ is composed of one pair of telocentric chromosome. The $\mathrm{X}$-chromosome is the longest metacentric chromosome carry secondary constrictions near the end in both females and males.
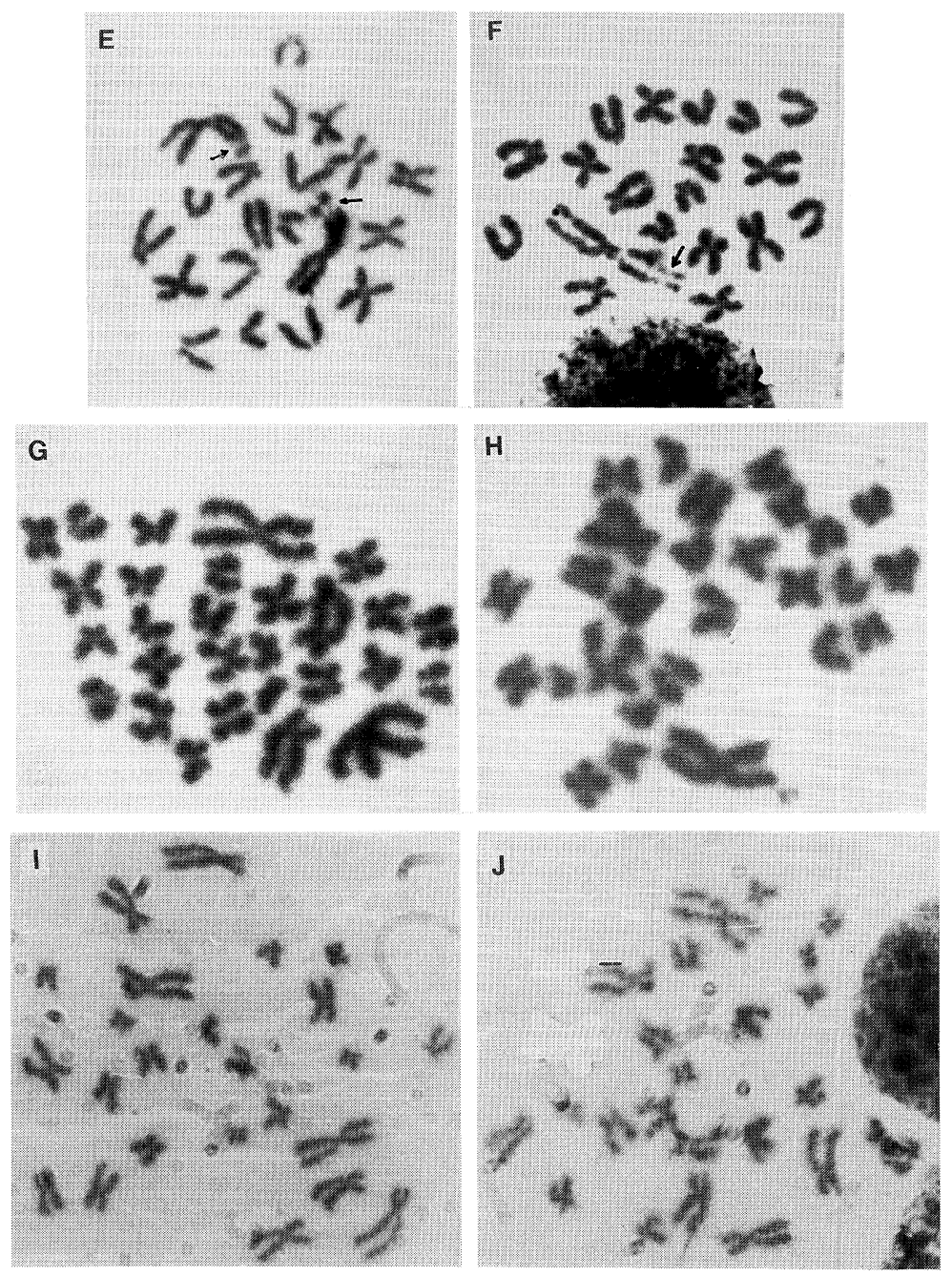

Fig. 1. Continued. 


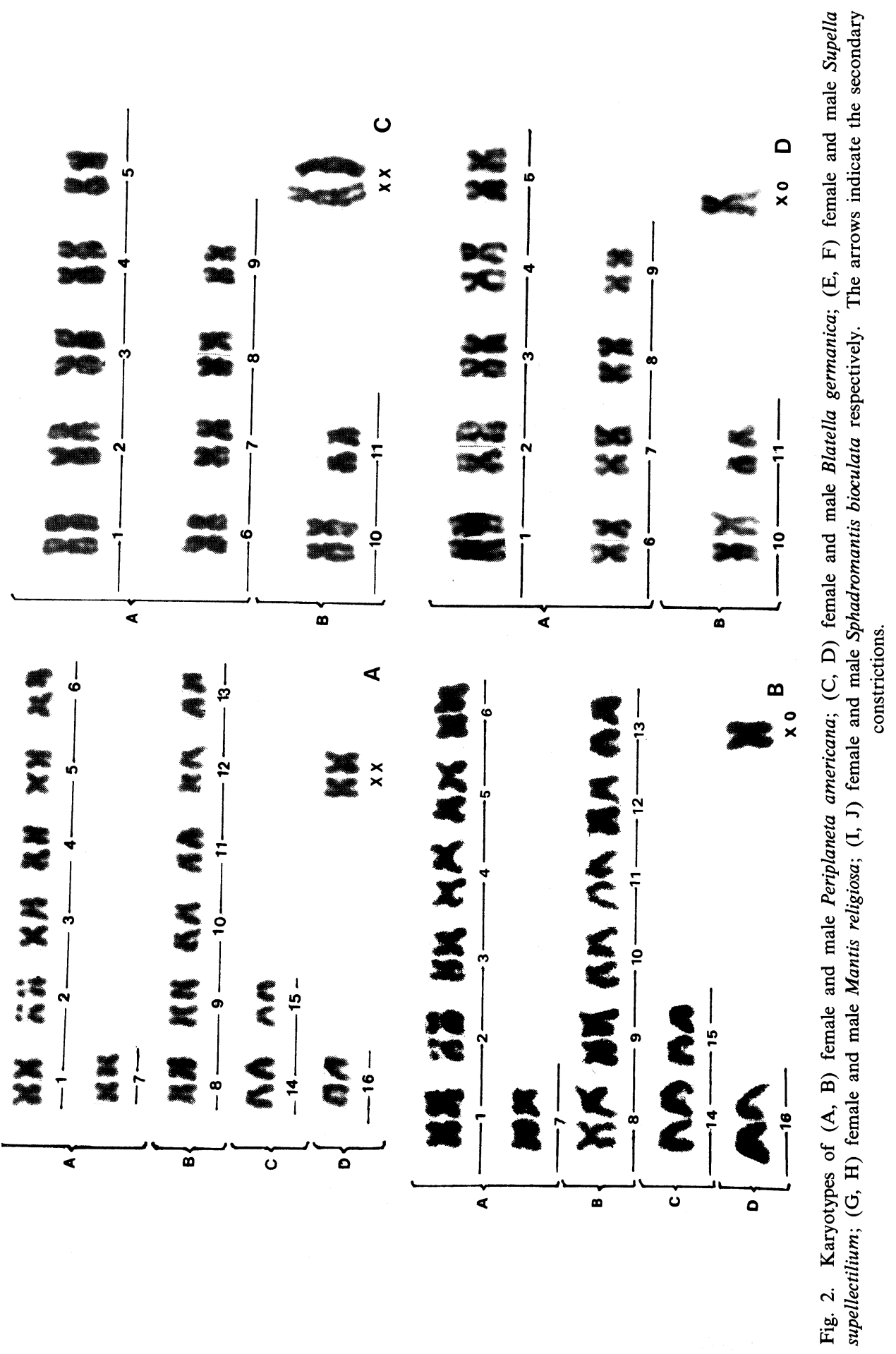




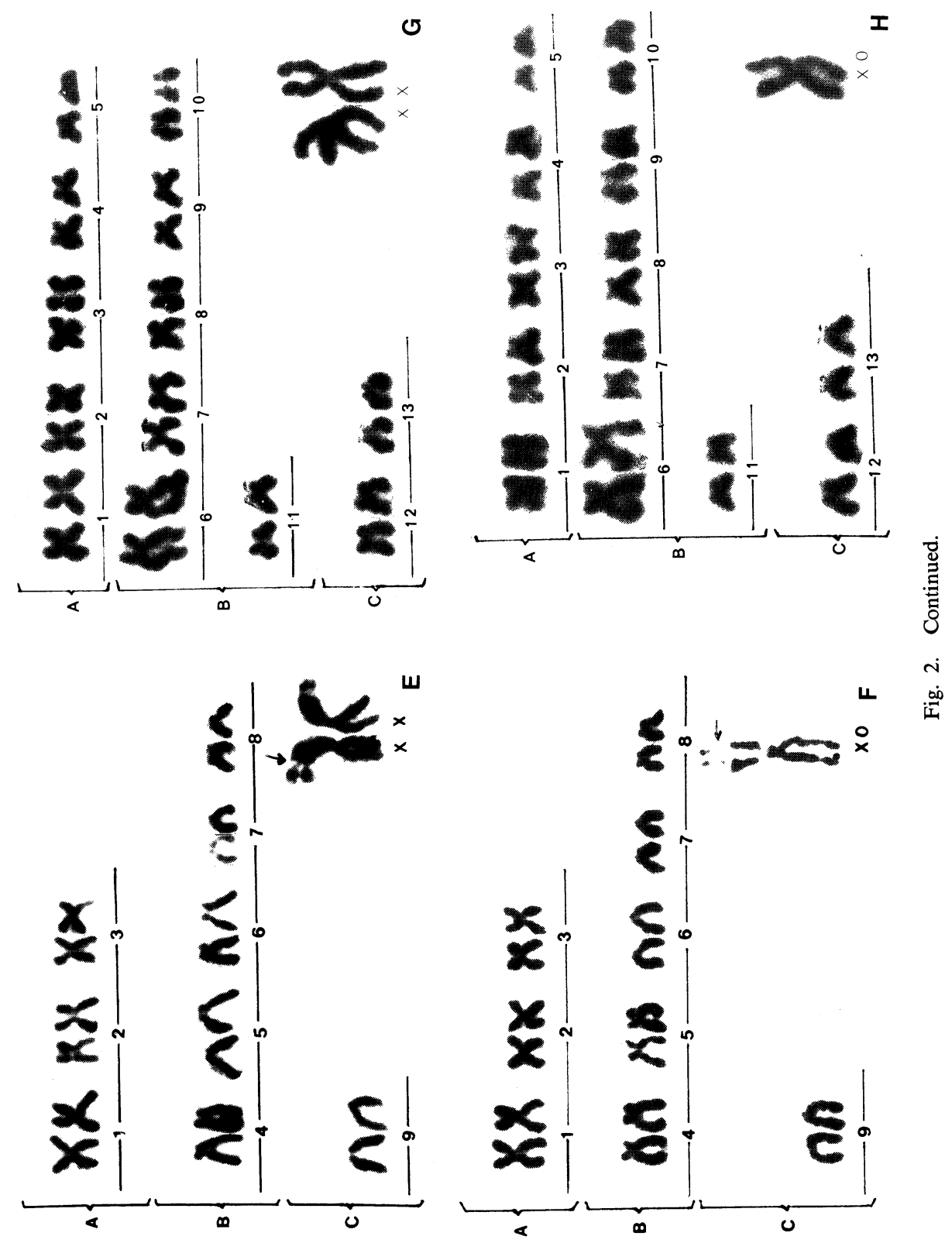



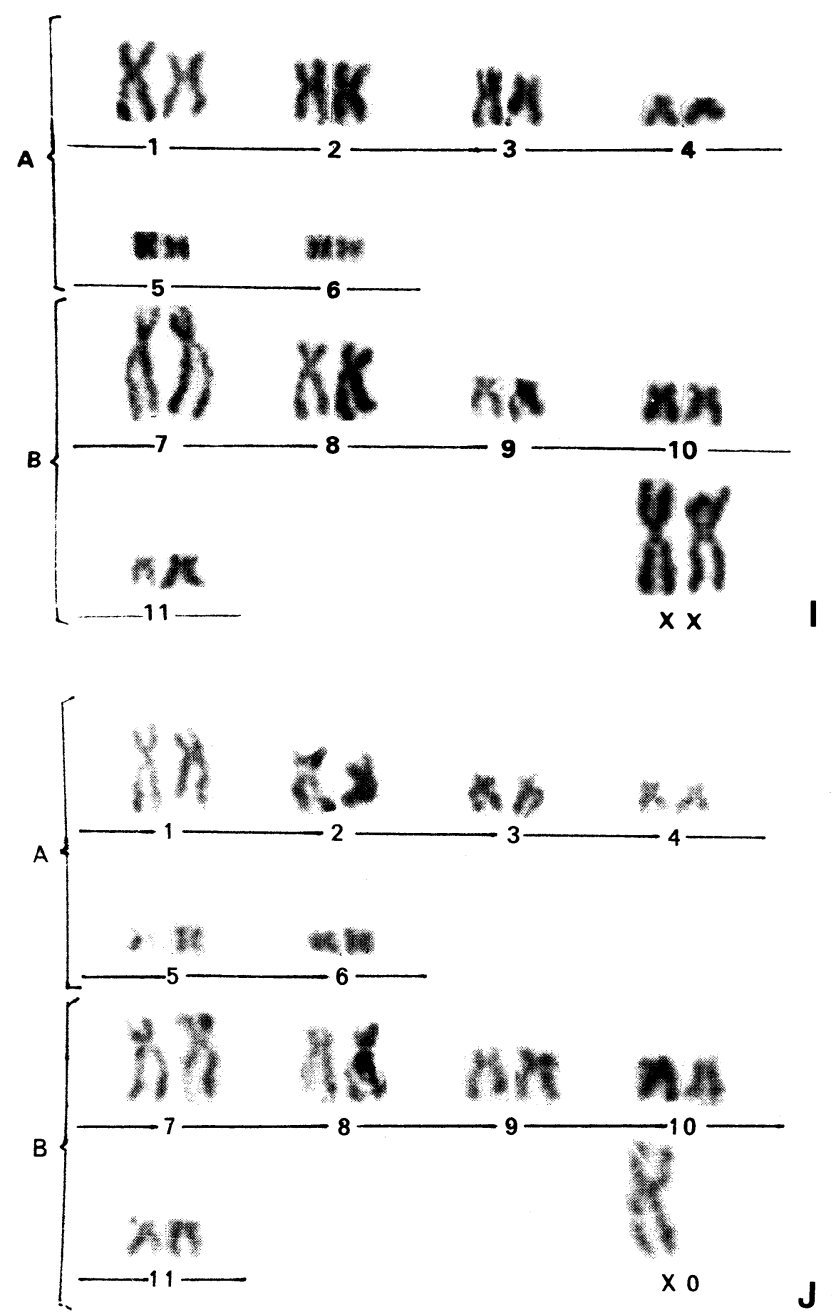

Fig. 2. Continued.

The metrical analysis of chromosome measurements of this species are given in Table 3.

\section{Family: Mantidae}

1. Mantis religiosa: The diploid chromosome number of this species was found to $26+$ $\mathrm{XX}$ in females and $26+\mathrm{XO}$ in males and $\mathrm{FN}=52$. The karyotype (Figs. 1G, H, 2G, H) showed three different groups of chromosomes: Group $\mathrm{A}$ is composed of five pairs of metacentric chromosomes graded desendingly according to size (arm ratio: 1.15-1.53), group $\mathrm{B}$ is composed of six metacentric chromosomes (arm ratio: 1.88-2.21) and group $\mathrm{C}$ which have two subtelcentric pairs (arm ratio: 3.33-3.90). The sex chromosome is large size metacentric. The chromosomal measurements of this species are given in Table 4.

2. Sphadromantis bioculata: A typical example of the cell spread and karyotype of a model sample of this species (Figs. 1I, J, 2I, J) were found that the diploid chromosome number was $22+\mathrm{XX}$ in females and $22+\mathrm{XO}$ in males and $\mathrm{FN}=44$. The karyotype showed two different groups: Group A is composed of five metacentric chromosomes of varying sizes (arm ratio: 1.25-1.43), group B consists of five metacentric pairs (arm ratio: 1.78-2.10). The $\mathrm{X}$-chromosome is large-sized metacentric. The chromosomal measurements for this species are 


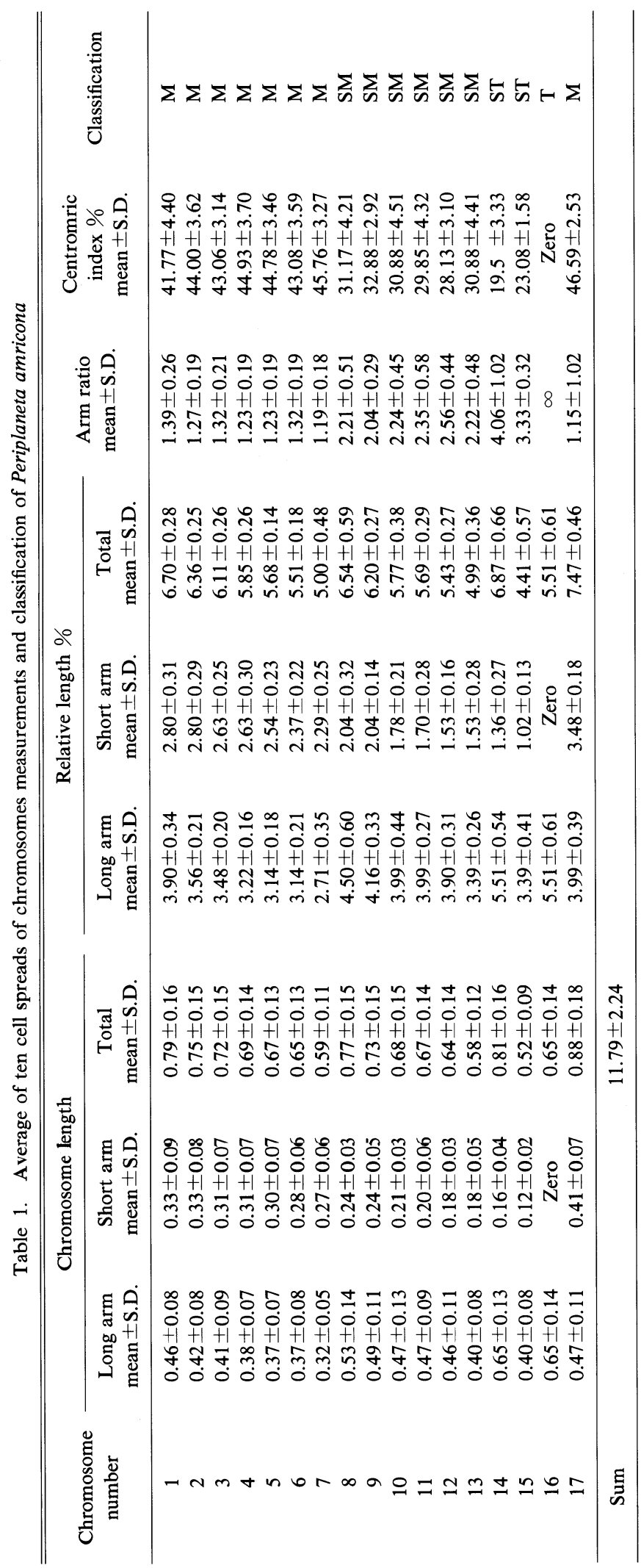



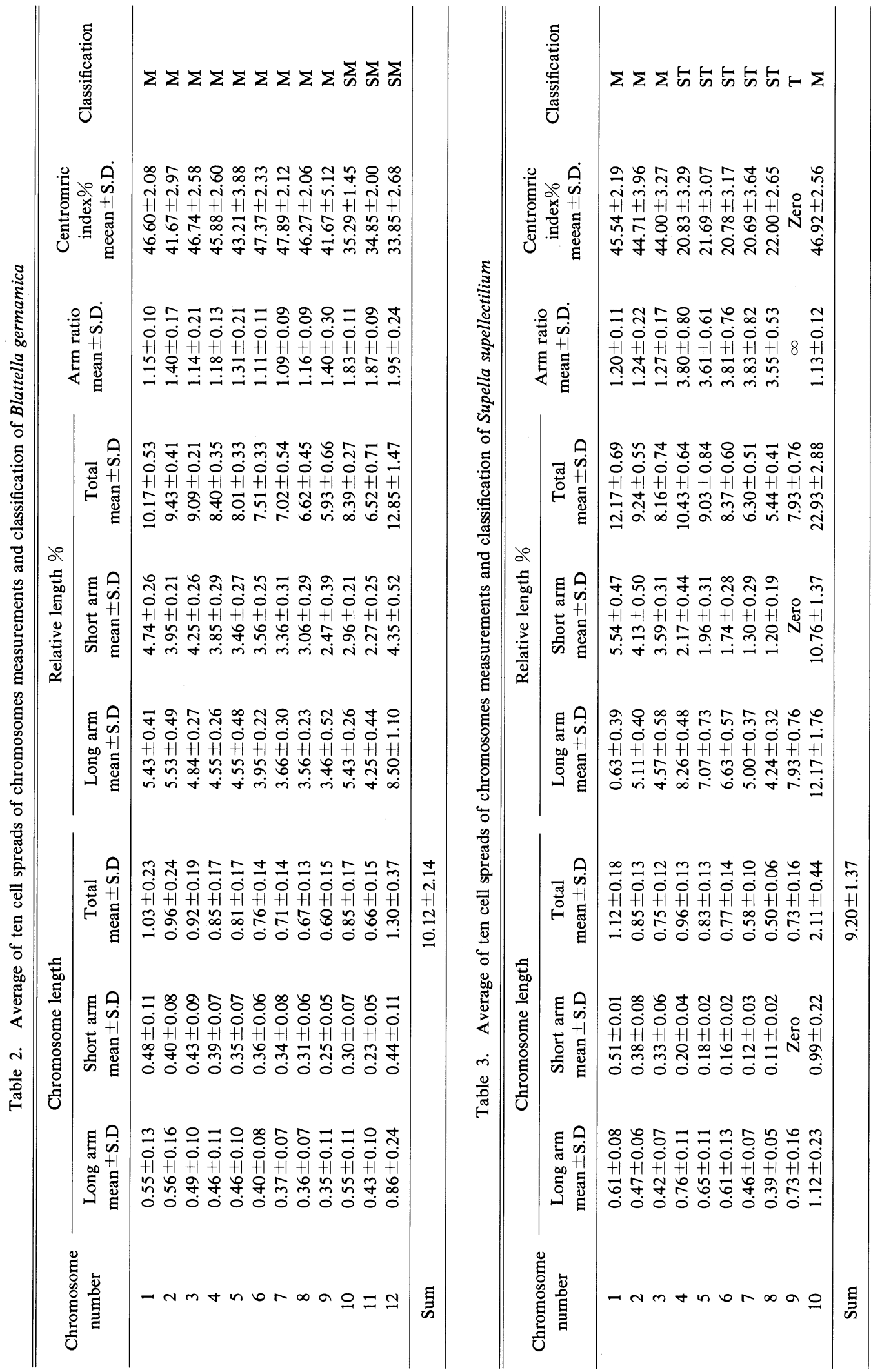


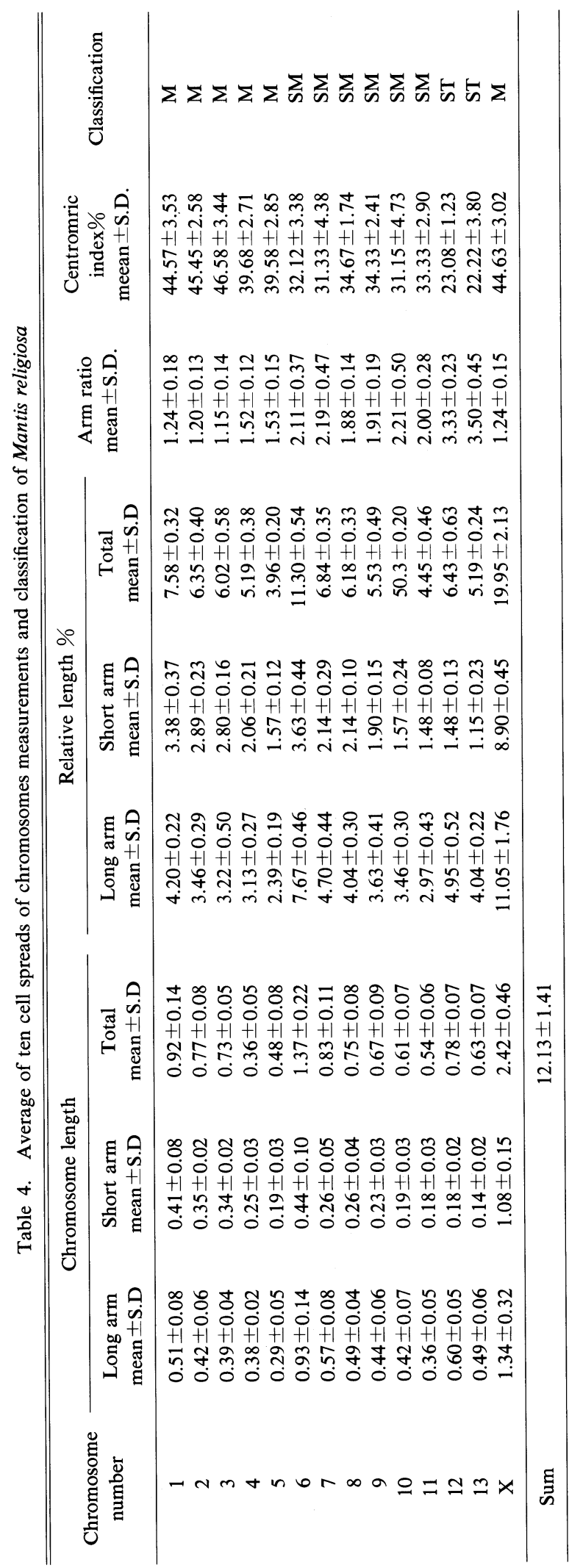




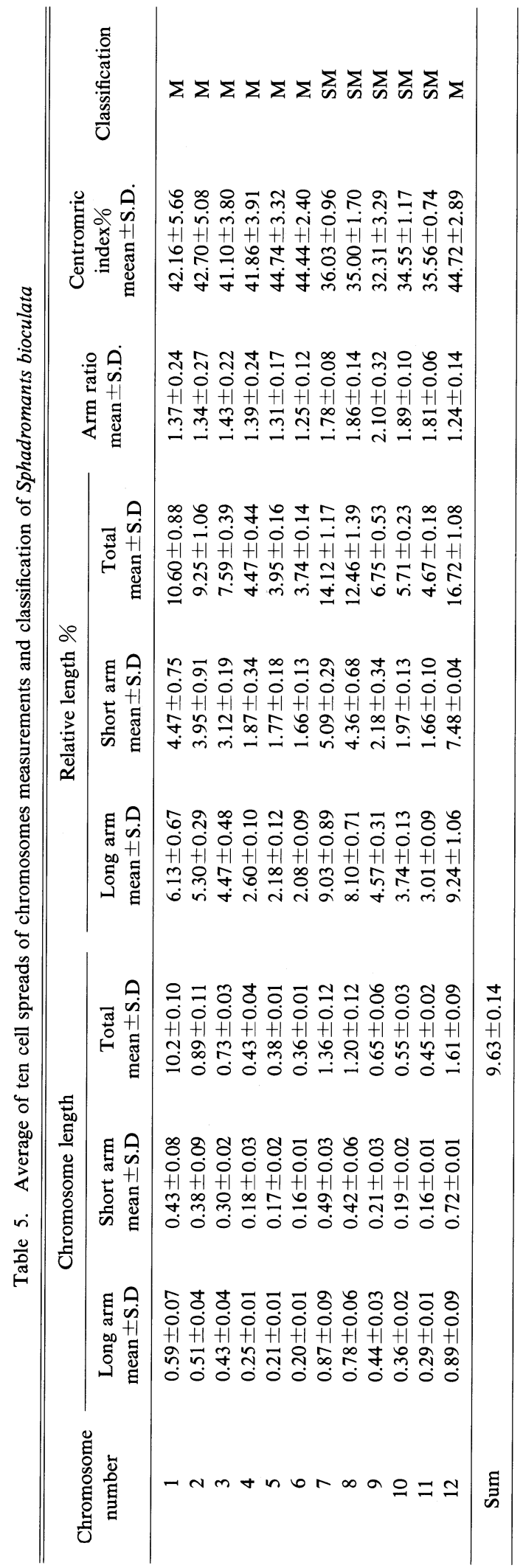


given in Table 5.

These results are in agreement with Cohen and Roth (1970) who reported that the diploid chromosome number in order Dictyoptera ranging from 16 to 80 in females and 15 to 79 in males and the X-chromosome is apparently the largest chromosome.

The authors concluded from these results that, the chromosomal analysis provides innumerable examples of clear-cut differences between the karyotypes of species so similar morphologically that they are barley or not at all distinguishable by classical taxonomical methods.

\section{Summary}

Chromosomes in five species of the order Dictyoptera Periplaneta americana, Blattella germanica, Supella supellectilium, Mantis religiosa and Sphadromantis bioculata have been studied. In Periplaneta americana (Family Blattidae), the diploid chromosome number of $32+$ $\mathrm{XX}$ in Females and $32+\mathrm{XO}$ in males was observed, while the diploid chromosome number in the two species Blattella germanica and Supella supellectilium (Family Blattillidae) were $22+$ $\mathrm{XX}$ in female, $22+\mathrm{XO}$ males and $18+\mathrm{XX}$ in females, $18+\mathrm{XO}$ in males respectively. The diploid chromosome number for the two species Mantis religiosa and Sphadromantis bioculata (Family Mantidae) were determined to be $26+\mathrm{XX}$ in females, $26+\mathrm{XO}$ in males and $22+\mathrm{XX}$ in females, $22+\mathrm{XO}$ in males respectively. Karyotypic data for these five species had been studied in details. These results are reported for the first times in Egypt.

\section{References}

Cochran, D. G. and Ross, M. H. 1967a. Preliminary studies of the chromosomes of twelve cockroach species (Blattaria: Blattidae, Blattellidae, Blaberidae). Ann. Entomol. Soc. Amer. 60: 1265-1272.

- and - 1967b. Cockroach genetics, Chapter 12, p. 403-415. In J. W. Wright and R. Pal (ed.) Genetics of Insect Vectors of Disease. Elsevier Publ. Co., New York.

Cohen, S. and Roth, L. 1970. Chromosome numbers of the Blattaria. Ann. Entomol. Soc. Amer. 63: 1520-1547.

Galian, J., Ortiz, A. S. and Serrano, J. 1992. Karyotype of nine species of Cicinelini and cytotaxonomic notes on Cicindelinae (Coleoptera, Carabidae). Genetica 82: 17-24.

Levan, A., Fredga, K. and Sandbery, A. A. 1964. Nomenclature of centromeric position on chromosomes. Hereditas 52: 201-220.

Pizea, S. de Toledo. 1958. Cytological studies on Brazilian Blattidae. Caryologia 10: 415-442.

Salemaa, H. 1979. The chromosomes of Asellus aquaticus (L.). A technique for isopod karyology. Crustacean, 36: 316-318.

White, M. J. D. 1973, Animal cytology and evolution (3rd ed.). Cambridge University Press, Cambridge. 